\title{
Breast Blunt Duct Adenosis
}

National Cancer Institute

\section{Source}

National Cancer Institute. Breast Blunt Duct Adenosis. NCI Thesaurus. Code C6941.

Breast adenosis characterized by the presence of ducts with distended lumen and columnar cell metaplasia. 